\title{
Comparison of Japanese Nurses' and Care Workers' Scores on the Dialogue Preference Scales for Elderly (DPSE)
}

\section{Hiroko Shimizu}

Chronic Adult Nursing, School of Nursing, Faculty of Medicine, Kagawa University, Japan

\begin{abstract}
This study compared nurses' and care workers' scores on the Dialogue Preference Scales for Elderly (DPSE) created from data from nursing students in Japan. For this forward-looking, quantitative, questionnairebased study, data collection was conducted from 2010 to 2012 with care seminar participants in Japan. Participants were nurses $(\mathrm{n}=277 ; 36.96 \pm 10.33$ years old, males; $4.33 \%$ females; $95.66 \%)$ and care workers $(\mathrm{n}=83 ; 40.52 \pm 11.68$ years old, males; $25.30 \%$ females; 74.69$)$. The samples varied significantly in mean age $(p<0.05)$ and gender $(p<0.001)$. The number of years of experience was 139.94 for nurses with $\mathrm{SD}=10.99$ and 90.99 for care workers with SD $=45.44(p<0.001)$.
\end{abstract}

Data were gathered using the 15-item Dialogue Preference Scales for Elderly (DPSE or Shimizu scale), which assesses nurses' negative cognition and attitude tendencies during their conversations with elderly individuals [1]. The DPSE measures attributes and the four sub-concepts of bewilderment, anxiety, cognitive bias, and communication difficulty. Higher scores indicate more negative cognitions or attitudes (maximum score: 28). Data were descriptively analyzed using Pearson's $\chi^{2}$ test and student's $t$ test of confirmatory factors. Nurses' total scores (mean; 57.31, SD $=11.84$ ) were not significantly different than care worker's scores (mean; 57.58, SD $=12.25$ ), indicating that nurses, and care workers had a similar view of communicating with older people. However, the sub-concept of cognitive bias was significantly lower for nurses, as they likely had higher levels of ageism $(p<0.10)$. Additionally, the communication difficulty sub-concept also was significantly higher for nurses, possibly because they had been caring for much older patients with more severe illnesses $(p<0.01)$.

\section{Background and Purpose}

This research grew from the realities of Japan as an aging society. As of 2019, census data indicated that Japan's total population is now declining after peaking in 2010. Simultaneously, the percentage of older people in the population is steadily increasing. In 2012, $28.2 \%$ of the Japanese population was classified as elders. By 2019, this percentage had risen to $28.4 \%$. Furthermore, this percentage is projected to increase to $30.0 \%$ by 2025 and $35.3 \%$ by 2040 based on estimates from 2019. Moreover, Japan has the highest aging rate among 201 countries and regions [2]. The problems faced by Japan's aging population should be addressed in policy measures designed to help older people live independently and in good health for as long as possible. Supporting this goal, the Healthy Japan 21 policy was released in 2000, followed by the enactment of the Health Promotion Law in 2002.

Ageism can become a growing problem as the number of elderly people increases. Ageism refers to a cognitive bias toward older people and is a specific form of discrimination, such as racism and sexism. Butler [3] defined ageism as "a process of systematic stereotyping and discrimination against people because they are old." This type of bias, which results from cultural and social influences [4], can be difficult to correct through education. Indeed, ageism may be a particular problem in Japan, with Palmore [4] observing that the general Japanese population holds feelings of both respect and contempt for older people.

Services that promote the health of older people require nurses and care workers to maintain appropriate behaviors. Nurses' and care workers' can have an unconscious level of ageism, which may affect the older people in their care [5]. Ageism that manifests in a person's negative manners and behaviors towards older people can result in a number of problems [6]. It has been reported that ageism mainly appears in work, family life, social life, sexual life, and medical service interactions [6]. Because care workers often treat extremely vulnerable older people, they need to be keenly aware of the physical and psychoemotional effects of ageism [7]. Fortunately, it had been documented that training can help reduce ageism among nurses [8,9]. Perhaps such training also could help address ageism among other care staff.

To help address the problem of ageism among caregivers, Shimizu developed the Dialogue Preference Scales for Elderly (DPSE or Shimizu scale), which assesses nurses' negative cognition and attitude tendencies during their conversations with elderly individuals [10]. Others have reported that care workers and nurses may have similar age-based biases [5]. In order to examine this contention further, this quantitative study compared DPSE scores from a sample of nurses and care workers.

\section{Methods}

\section{Study design}

This quantitative study used a questionnaire-based comparative design.

${ }^{*}$ Corresponding Author: Prof. Hiroko Shimizu, Chronic Adult Nursing, Faculty of Medicine, Kagawa University, Kita-gun Miki-cho, Kagawa Prefecture, Japan; E-mail: hshimizu@med.kagawa-u.ac.jp

Citation: Shimizu H (2020) Comparison of Japanese Nurses' and Care Workers Scores on the Dialogue Preference Scales for Elderly (DPSE). Int J Nurs Clin Pract 7: 328. doi: https://doi.org/10.15344/2394-4978/2020/328

Copyright: (c) 2020 Shimizu. This is an open-access article distributed under the terms of the Creative Commons Attribution License, which permits unrestricted use, distribution, and reproduction in any medium, provided the original author and source are credited. 


\section{Setting and sample}

This cross-sectional study used a questionnaire-based survey administered to a sample of nurses and care workers between 2009 and 2012. To minimize the potential for geographical bias, the study was conducted with respondents from several investigation venues in Japan. The sample included nurses and care workers who attended dementia seminars in Osaka and Tokyo and nurses from one medium-sized hospital in Shikoku serving patients with work-related accidents. Because the respondents had volunteered to take the survey, they became part of the random sample. It has been shown that nurses who care for older people with disabilities (e.g., dementia) may have a bias against ailing older people [11]. Therefore, this study targeted nurses prone to such prejudice. All of the respondents were currently practicing clinical nursing. Nurses with cognitive impairments were excluded.

\section{Ethical considerations}

Because the care worker's information was derived from anonymous data collected at a seminar in Shikoku Island from 2010-2011, the rules of the researcher's institution stipulate that ethical permission was not required in this case. Ethics approval for collecting the nurses' data was obtained from the K University Ethics Committee (2014-059). The nurses who chose to participate provided consent and were not directly approached by the primary researcher. Instead, an assistant explained the study and distributed consent forms and questionnaires. Questionnaire responses were anonymous and details about the respondents or their institutions were not recorded.

\section{Measurements/instruments}

The DPSE was used for this study. The DPSE's four sub-conceptsassess respondents' relationships with older people-have been found to be reliable [1]. These sub-concepts are bewilderment (shown through uncertainty), anxiety, cognitive bias (associated with ageism), and difficulty in communication.

No other standardized scale has been found to be comparable to the DPSE. However, concurrent validity was detected for the DPSE's "anxiety in relationships" item and the "authoritative anxiety" item in the Social Anxiety Scale in Social Situations [12]. The DPSE also demonstrated predictive validity for the targeted achievement level for nursing students' clinical training. The total coefficient of reliability (a) was 0.811 , thus confirming internal consistency reliability. The coefficients of reliability $(\alpha)$ were 0.764 for bewilderment, 0.687 for anxiety, 0.671 for cognitive bias, and 0.670 for communication difficulty.

\section{Data collection/procedures}

The 15-item DPSE (Table 1) used in this study collects details about base attributes and measures 15 key items (including anxieties, knowledge, behavior, and value systems) on a seven-point, Likerttype scale. Higher scores on this scale indicate more negative thoughts and attitudes about communicating with older people. Unlike other scales, the DPSE measures not only the caregivers' attitudes, but it also considers their educational levels and cultural characteristics [1]. The scale's validity and reliability were confirmed with data collected

\begin{tabular}{|c|c|c|}
\hline $\begin{array}{l}1 . \\
2 . \\
3 . \\
4 .\end{array}$ & $\begin{array}{l}\text { Age ( ) } \\
\text { Clinical experience (years) ( ) } \\
\text { Have you experienced living with older people? (Presently yes / In the past yes / No) }\end{array}$ & \\
\hline \multicolumn{3}{|c|}{$\begin{array}{l}\text { Please respond to the questions using the following scale that assumes that the distance between numbers is equal. Circle one number ( } 1-7 \text { ) that } \\
\text { best represents your opinion: } 1 \text { (Strongly disagree) }-2-3-4 \text { (Neither agree nor disagree) }-5-6-7 \text { (Strongly agree). }\end{array}$} \\
\hline No. & Questions & $\begin{array}{l}\text { Grading } \\
\text { (7-point Likert-type) } \\
\text { 1: strongly disagree } \\
7: \text { strongly agree }\end{array}$ \\
\hline 1. & I am aware of a major age gap with older clients and find it difficult to think of suitable topics of conversation. & $1-2-3-4-5-6-7$ \\
\hline 2. & I am uncertain how seriously I should listen to older clients. & $1-2-3-4-5-6-7$ \\
\hline 3. & $\begin{array}{l}\text { I always try to maintain a loud voice when I talk to older clients, so I tend to say things that are not really what I } \\
\text { want to say. }\end{array}$ & $1-2-3-4-5-6-7$ \\
\hline 4. & I do not know how to react when older clients repeat themselves. & $1-2-3-4-5-6-7$ \\
\hline 5. & In conversation, when older clients talk about history, I am not sure what to do because my knowledge is limited. & $1-2-3-4-5-6-7$ \\
\hline 6. & I worry about the vision of older clients. How do they see and how much do they see? & $1-2-3-4-5-6-7$ \\
\hline 7. & When talking to older clients, I wonder whether my voice is the right volume and if my tone is appropriate. & $1-2-3-4-5-6-7$ \\
\hline 8. & When talking to older clients, I worry that I may exhaust them. & $1-2-3-4-5-6-7$ \\
\hline 9. & I wonder how older clients view us, the younger generation. & $1-2-3-4-5-6-7$ \\
\hline 10. & Older clients just want someone to listen to them all the time. & $1-2-3-4-5-6-7$ \\
\hline 11. & Older clients want somebody to listen to them and they want to talk about themselves. & $1-2-3-4-5-6-7$ \\
\hline 12. & It seems that once older clients start talking. They often do not stop. & $1-2-3-4-5-6-7$ \\
\hline 13. & It is difficult to know how to speak to and deal with older clients who have dementia. & $1-2-3-4-5-6-7$ \\
\hline 14. & I find it hard to hold conversations with older clients with hearing difficulties. & $1-2-3-4-5-6-7$ \\
\hline 15. & I find it hard to communicate with older clients with total aphasia. & $1-2-3-4-5-6-7$ \\
\hline
\end{tabular}

Table 1: Dialog Preference Scales for Elderly Questionnaire. 
from Japanese nursing students. These data later were confirmed in a population of nurses [1].

\section{Data analysis}

Data were analyzed as descriptive statistics. As appropriate, Pearson's $\chi^{2}$ test and student's $t$ test of confirmatory factors were performed. Data are presented as mean (IBM, SPSS, standard deviation version 26) unless otherwise specified.

\section{Results}

Participants were nurses $(\mathrm{n}=277 ; 36.96 \pm 10.33$ years old; males $4.33 \%$; females $95.66 \%)$ and care workers $(\mathrm{n}=83 ; 40.52 \pm 11.68$ years old; males $25.30 \%$; females 74.69 ). The samples varied significantly in mean age $(p<0.05)$ and gender $(p<0.001)$. The number of years of experience was 139.94 for nurses with $\mathrm{SD}=10.99$ and 90.99 for care workers with $\mathrm{SD}=45.44(p<0.001)$.

Data were gathered using the 15-item DPSE, which measures attributes and four sub-concepts (bewilderment, anxiety, cognitive bias, and communication difficulty). Higher scores indicate more negative cognitions or attitudes (maximum score: 28). Data were descriptively analyzed using Pearson's $\chi^{2}$ and Student's $t$-tests.

Nurses' total scores (mean; $57.31, \mathrm{SD}=11.84$ ) were not significantly different than those of the care worker (mean: $57.58, \mathrm{SD}=12.25$ ). This finding indicated that the nurses and care workers have similar views about communicating with older people.

The average sub-concept scores (Table 2) were as follows: bewilderment (n. s.) $13.42(\mathrm{SD}=5.09)$ for nurses and $14.24(\mathrm{SD}=$ 5.27) for care workers; anxiety (n. s.) $16.29(\mathrm{SD}=5.27)$ for nurses and $16.14(\mathrm{SD}=5.90)$ for care workers; cognitive bias $(p<0.10) 13.27$ $(\mathrm{SD}=3.90)$ for nurses and $14.07(\mathrm{SD}=3.65)$ for care workers; and communication difficulty $(p<0.05) 14.34(\mathrm{SD}=4.14)$ for nurses and $13.12(\mathrm{SD}=4.09)$ for care workers.

In the cognitive bias sub-concept, care workers had higher scores on item 10 (older clients just want someone to listen to them all the time; $p<0.10$ ) and item 11 (older clients want somebody to listen to them and they want to talk about themselves; $p<0.05$ ). In the communication difficulty sub-concept, nurses had higher scores on item 13 (it is difficult to know how to speak to and deal with older clients who have dementia; $p<0.001$ ).

\section{Discussion}

The results for the bewilderment and anxiety sub-concepts did not differ significantly between nurses and care workers. In other words, there was no noteworthy differences between these two groups in confusion and anxiety due to lack of knowledge. Survey respondents should have had sufficient knowledge to interact with the elderly, as the nurses had an average of 10 years and care workers an average of eight years of experience.
The scores for the cognitive bias sub-concept represents the expression of ageism. Items 10 and 11 are false beliefs, as not all seniors want someone to talk to them, or to talk about themselves all the time. Therefore, it can be concluded that these care workers generally hold negative feelings about older people.

Results for the ageism sub-concept were influenced by respondent age. The care worker respondents were significantly older than the nurse respondents. While it seems logical to assume that the older care workers would be less ageist than the younger nurses, the opposite was true. Therefore, this finding clearly indicates that, compared to nurses, care workers have a more prejudicial attitude about older people.

These results prompt the question, why were these care workers more prejudicial than the nurses? Because research has shown that ageism, which can be unconscious, may compromise older people's health [5], it should be considered a problem. In contrast, Shimizu [10] found that the more familiar caregivers are with older people, the more ageism they have. In fact, it has been reported that those who want to care for older people are more ageist [13]. While care workers in Japan may be familiar with older people, they need to learn if they have ageism and, if so, how it can compromise older people's health. Furthermore, it is necessary to train care workers in a way that improves their perception of old age, so that they can take a positive view of becoming older. It has been said that this is the main role of the gerontology specialty [14].

The communication difficulty sub-concept was affected by job description. Item 13 indicated that nurses found it more difficult to interact with dementia patients than did care workers. This finding was surprising given the fact that these nurses had a special focus on dementia care. This finding may be due to the fact that, compared to care workers, these nurses care for patients with more severe dementia and more profound disabilities, who may not be able to communicate. Indeed, patients with severe, advanced dementia patients are unable to speak. Caring for such patients likely is very difficult for these nurses.

\section{Conclusion}

Including participants from several geographic areas contribute to the strength of a study. In this study, the nurses and care workers exhibited approximately the same levels of bewilderment and anxiety, despite having years of caregiving experience. These are reasonable results, consistent with a previous report [10]. The DPSE predicted these issues. The Shimizu report explained that longer experience with older individuals increased knowledge about them and reduced the bewilderment and anxiety regarding the dialogue with them. Based on this study's results, the DPSE-developed with nursing students-has achieved appropriate results with another group of caregivers-care workers. If the DPSE scale is used, application to the education of care workers can be expected. The DPSE developed for nurses could be used to improve their dialogue and attitude toward the elderly.

\section{Implications for Practice}

While experienced nurses and care workers had similar levels of

\begin{tabular}{|c|c|c|c|c|c|}
\hline & $\mathrm{n}$ & Bewilderment & Anxiety & Cognitive bias & Communication difficulty \\
\hline Nurses & 277 & $13.42 \pm 5.09-$ & $16.29 \pm 5.27$ & $13.27 \pm 3.90-$ & $14.34 \pm 4.14$ \\
\hline Care-workers & .83 & $14.24 \pm 5.27$ n.s. & $16.14 \pm 5.90$ & $14.07 \pm 3.65$ & $13.12 \pm 4.09$ \\
\hline
\end{tabular}


Citation: Shimizu H (2020) Comparison of Japanese Nurses' and Care Workers' Scores on the Dialogue Preference Scales for Elderly (DPSE). Int J Nurs Clin Pract 7: 328. doi: https://doi.org/10.15344/2394-4978/2020/328

bewilderment and anxiety, care workers are more likely to compromise the health of older people if they have an unconscious prejudice. In this case, these workers need training to improve their views on aging and caring for elderly patients.

\section{Acknowledgments}

The author would like to thank Enago (www.enago.jp) for English language review.

\section{Competing Interests}

The author declare that there is no competing interests regarding the publication of this article.

\section{References}

1. Shimizu H (2010) Validity and reliability of Dialogue Preference Scales for Elders. Journal of Japan Academy of Gerontological Nursing 14: 34-41.

2. National Institute of Population and Social Security Research (2017) Population Projections for Japan: 2016-2065.

3. Butler RN (1995) Ageism. In GL Maddox, The Encyclopaedia of Aging (2nd ed). New York: Springer.

4. Palmore EB (1999) Types of ageism. In EB Palmore (Ed). Ageism: Negative and Positive. New York, NY: Springer Publishing Company, Inc.

5. Simkins C (2007) Ageism's Influence on Health Care Delivery and Nursing Practice. Journal of Nursing Student Research 1: 5 .

6. Bulut $E$, Çilingir D (2016) Ageism and reflections of nursing care. TAF Preventive Medicine Bulletin 15: 446-449.

7. Nemmers TM (2009) The Influence of ageism and ageist stereotypes on the elderly 22: 11-20.

8. Selda Y, Tug OA (2015) Nurses' Attitudes towards Older People: Report from a Single Institution Study. International Journal of Physical Medicine \& Rehabilitation.

9. Furlan J, Craven B, Ritchie R, Coukos L, Fehlings M, et al. (2009) Attitudes towards the older patients with spinal cord injury among registered nurses: A cross-sectional observational study. Spinal Cord 47: 674-680.

10. Shimizu $\mathrm{H}$ (2007) The problems and characteristics of communication between nursing students and the elderly. Journal of Japan Academy of Gerontological Nursing 11: 56-63.

11. Banerjee S, Manna R, Gangai N, Alici Y, Nelson C et al. (2018) Geriatric communication skills training for clinicians to improve the care of older cancer patients. Journal of the American Geriatrics Society 66: S150.

12. Mori, I., \& Tanno, Y. (2001). Reliability and validity of creating Social Anxiety Scale in Social Situations scale. Journal of Health Research 14: 23-31.

13. Shinan-Altman S, Soskolne V, Ayalon L (2020) Becoming a home care worker: Job-seekers' push and pull factors. Research on Aging 42: 62-71.

14. Shimizu $\mathrm{H}$, Nojiri M (2005) Student training for better communication with elderly using simulated patients. Journal of Human Care Studies. 6: 45-54.

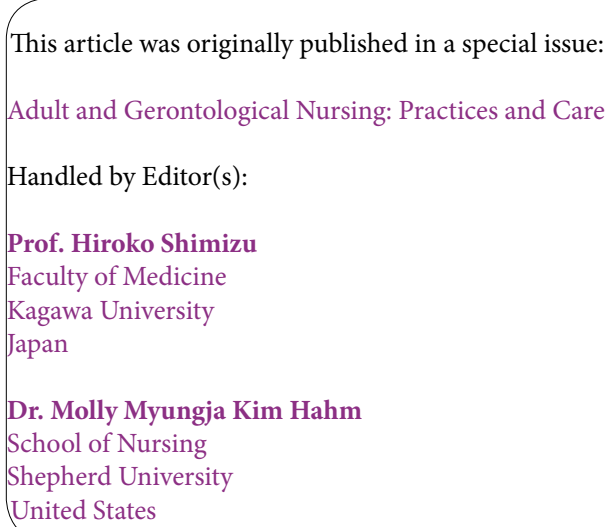

